\title{
Understanding neural activity through piece-wise linear models
}

\author{
Ana Maria Gheorghe*, Stephen Coombes \\ From Nineteenth Annual Computational Neuroscience Meeting: CNS*2010 \\ San Antonio, TX, USA. 24-30 July 2010
}

In recent years there has been an upsurge of interest in fitting real spike train data to nonlinear integrate-and-fire (IF) models [1]. Such models are often preferred over more detailed conductance based models for their small number of parameters and low computational overhead. Moreover, the nonlinearities in such models can often be caricatured by piece-wise linear (pwl) forms, allowing the construction of action potential shapes in closed form as well as the calculation of phase response curves. With the inclusion of pwl adaptive currents they can also support bursting behavior, though remain amenable to mathematical analysis at both the single neuron [2] and network level [3]. In fact pwl models caricaturing conductance based models such as that of Morris-Lecar have also been studied for some time now and also recently been shown to be mathematically tractable at the network level [4].

In this work we give a summary of recent progress in understanding pwl neuron models of both conductance and IF type. In particular we focus on pwl models of FitzHugh-Nagumo type and describe in detail the mechanism for a canard explosion. As regards IF models we focus on a variant of the adaptive absolute IF model that can support bursting. In both cases we study dynamics at the network level in the presence of gap junction coupling. In particular we uncover the conditions for gap-induced transitions between synchrony and asynchrony analytically.

Published: 20 July 2010

\section{References}

1. Badel L, Lefort S, Brette R, Petersen C, Gerstner W, Richardson MJE: Dynamic I-V Curves Are Reliable Predictors of Naturalistic PyramidalNeuron Voltage Traces. J Neurophysiol 2008, 99:656-666.

* Correspondence: pmxamg@nottingham.ac.uk

School of Mathematical Sciences, University of Nottingham, Nottingham, NG7 2RD, UK
2. Touboul J, Brette R: Dynamics and bifurcations of the adaptive exponential integrate-and-fire model,. Biological Cybernetics 2008, 99(45):319-340.

3. Coombes S, Zachariou M: Gap junctions and emergent rhythms. Coherent Behavior in Neuronal Networks Springer, Computational Neuroscience seriesRubin, Josic, Matias, Romo 2009.

4. Coombes S: Neuronal networks with gap junctions: A study of piecewise linear planar neuron models. SIAM Journal on Applied Dynamical Systems 2008, 7:1101-1129.

doi:10.1186/1471-2202-11-S1-P26

Cite this article as: Gheorghe and Coombes: Understanding neural activity through piece-wise linear models. BMC Neuroscience 2010 11(Suppl 1):P26.
Submit your next manuscript to BioMed Central and take full advantage of:

- Convenient online submission

- Thorough peer review

- No space constraints or color figure charges

- Immediate publication on acceptance

- Inclusion in PubMed, CAS, Scopus and Google Scholar

- Research which is freely available for redistribution

Submit your manuscript at www.biomedcentral.com/submit
Ciomed Central 